\title{
Expression of osteoblastic phenotype in periodontal ligament fibroblasts cultured in three-dimensional collagen gel
}

\author{
Luciana Bastos ALVES ${ }^{1}$, Viviane Casagrande MARIGUELA', Márcio Fernando de Moraes GRISI', Sérgio Luiz \\ Scaombatti de SOUZA ${ }^{1}$, Arthur Belém NOVAES JUNIOR ${ }^{1}$, Mário TABA JUNIOR ${ }^{1}$, Paulo Tambasco de OLIVEIRA², \\ Daniela Bazan PALIOTO²
}

1- Department of Oral Surgery and Periodontology, Ribeirão Preto School of Dentistry, University of São Paulo, Ribeirão Preto, SP, Brazil.
2- Department of Morphology, Stomatology and Physiology, Ribeirão Preto School of Dentistry, University of São Paulo, Ribeirão Preto, SP, Brazil.

Corresponding address: Luciana Bastos Alves - Departamento de Cirurgia e Traumatologia Buco-Maxilo-Facial e Periodontia - Faculdade de Odontologia de Ribeirão Preto - Universidade de São Paulo - Av. do Café, s/n - Ribeirão Preto - SP - 14040-904 - Brazil - Fax: +55 1636024788 - e-mail: luciana.bastos@ hotmail.com

Submitted: November 14, 2014 - Modification: January 31, 2015 - Accepted: February 18, 2015

\section{ABSTRACT}

\begin{abstract}
$\mathrm{O}$ bjective: To investigate the influence of a three-dimensional cell culture model on the expression of osteoblastic phenotype in human periodontal ligament fibroblast (hPDLF) cultures. Material and Methods: hPDLF were seeded on bi-dimensional (2D) and three-dimensional (3D) collagen type I (experimental groups) and and on a plastic coverslip (control) for up to 14 days. Cell viability and alkaline phosphatase (ALP) activity were performed. Also, cell morphology and immunolabeling for alkaline phosphatase (ALP) and osteopontin (OPN) were assessed by epifluorescence and confocal microscopy. The expression of osteogenic markers, including alkaline phosphatase, osteopontin, osteocalcin (OC), collagen I (COL I) and runt-related transcription factor 2 (RUNX2), were analyzed using real-time polymerase chain reaction (RT-PCR). Mineralized bonelike nodule formation was visualized by microscopy and calcium content was assessed quantitatively by alizarin red assay. Results: Experimental cultures produced an increase in cell proliferation. Immunolabeling for OPN and ALP in hPDLF were increased and ALP activity was inhibited by three-dimensional conditions. OPN and RUNX2 gene expression was significantly higher on 3D culture when compared with control surface. Moreover, ALP and COL I gene expression were significantly higher in three-dimensional collagen than in 2D cultures at 7 days. However, at 14 days, 3D cultures exhibited ALP and COL I gene expression significantly lower than the control, and the COL I gene expression was also significantly lower in 3D than in 2D cultures. Significant calcium mineralization was detected and quantified by alizarin red assay, and calcified nodule formation was not affected by tridimensionality. Conclusion: This study suggests that the 3D cultures are able to support hPDLF proliferation and favor the differentiation and mineralized matrix formation, which may be a potential periodontal regenerative therapy.
\end{abstract}

Keywords: Collagen. Fibroblasts. Periodontal ligament.

\section{INTRODUCTION}

Periodontitis is an inflammatory disease caused by a microbial challenge in a susceptible host. Due to the inflammation, periodontal ligament $(P D L)$, bone and cementum are destroyed, which eventually might lead to tooth loss. Current treatments of periodontitis consist of removal of plaque and calculus, which indeed prevents further disease progression, but these treatments do not regenerate the lost tissues. Instead, histological studies have shown epithelial downgrowth, indicating it is a mere reparative type of healing ${ }^{3}$. Many recent studies focus on treatment strategies to achieve actual regeneration of the PDL rather than repair. 
Periodontal tissue engineering has emerged as a promising approach to treat the loss of periodontal tissue. Fibroblasts are predominant in the periodontal ligament and are thought to be responsible for the homeostasis and regeneration of the tissue. Human ligament periodontal fibroblasts (hPDLF) are multipotent cells and have the potential to differentiate into osteoblasts or cementoblasts according to the microenvironment ${ }^{22}$. It is also reasonable to hypothesize that an osteoblastic phenotypic expression in hPDLF in vitro could correspond to a positive in vivo response, such as the promotion of mineralized tissue formation induced by the environment. However, the monolayer cultures of hPDLF are completely different from the three-dimensional (3D) environments ${ }^{7,12,28}$.

In order to simulate the three-dimensional (3D) environment of cells with extracellular matrix in vivo, researchers have been looking for appropriate scaffolds or carriers for cell implantation. Collagen has been used for tissue engineering purposes. This is due to its excellent biocompatibility and safety associated with its biological characteristics, such as biodegradability and weak antigenicity materials in the cell. Cells can be readily seeded into 3D collagen scaffolds, as sponges, membranes or gels, cultured and then introduced into a defect site for tissue repair and regeneration ${ }^{29}$.

This study focused on evaluating the effect of three-dimensionality on hPDLF behavior when cultured on 2D and 3D collagen gel, whether the collagen could induce hPDLF to an osteoblastic phenotype.

\section{MATERIAL AND METHODS}

THE HPDLF were seeded on three-dimensional collagen gel (3D) and collagen-coated coverslips (2D) (experimental groups), and on a plastic coverslip (control group) (ThermanoxTM, Nunc, NY, USA).

\section{Cell isolation and culture}

hPDLF were isolated from freshly extracted second premolars from patients who underwent orthodontic treatment, after informed consent was obtained, using explant cultures as previously described ${ }^{26}$. Briefly, premolars were extracted, washed twice with saline, and then hPDLF fragments from the middle third of the root were curetted. After being washed, periodontal ligament tissues were cut into small pieces, plated in $25 \mathrm{~cm}^{2}$ flasks (Fisher Scientific, PA, USA) and cultured in Dulbecco's modified Eagle medium (DMEM) (GIBCO-Invitrogen, Carlsbad, CA, USA) containing $10 \%$ fetal bovine serum (FBS) (GIBCO-Invitrogen), $50 \mathrm{mg} \mathrm{mL}^{-1}$ vancomycin (Acros Organics, Gell, Belgium), $5 \mu \mathrm{g} \mathrm{mL}^{-1}$ gentamycin (GIBCO-Invitrogen) and $50 \mathrm{ng} \mathrm{mL}^{-1}$ fungizone (GIBCO-Invitrogen).

Cultures were maintained in a humidified atmosphere with $5 \% \mathrm{CO}_{2}$ and $95 \%$ air at $37^{\circ} \mathrm{C}$, and the medium was changed every 3 days. When confluent, cells surrounding the explants were harvested using $0.05 \%$ trypsin and $0.02 \%$ ethylenediaminetetraacetic acid (EDTA) (GIBCOInvitrogen) in phosphate buffered saline (PBS) and transferred to $75 \mathrm{~cm}^{2}$ flasks (Fisher Scientific). Cells between passages 1-3 were seeded by the overlay method on different groups at a density of $2 \times 10^{4}$ cells per well for periods of up to 14 days in $1 \mathrm{~mL}$ of osteogenic medium $\alpha$-MEM supplemented with $10 \%$ FBS, $0.3 \mathrm{mg} / \mathrm{mL}$ fungizone, $50 \mu \mathrm{g} / \mathrm{mL}$ gentamycin, $5 \mu \mathrm{g} / \mathrm{mL}$ of ascorbic acid (GIBCO-Invitrogen) and 7 mM $\beta$-glycerophosphate (Sigma, St. Louis, USA) and dexamethasone $10^{7}$ (Sigma) and maintained in a humidified atmosphere with $5 \% \mathrm{CO}_{2}$ and $95 \%$ air at $37^{\circ} \mathrm{C}$. The culture medium was changed every 2-3 days. All procedures were approved by the Research Ethics Committee of Ribeirão Preto School of Dentistry, University of São Paulo, Brazil (process No. 2009.1.1206.58.3).

\section{Preparation of scaffolds}

Three-dimensional scaffolds were prepared by mixing the collagen solution $(3 \mathrm{mg} / \mathrm{mL}$, bovine Col I) (BS Science, MS, USA) with a solution of $1 \mathrm{M}$ of $\mathrm{NaOH}, 186 \mathrm{mM} \mathrm{NaHCO}$ and a-minimum essential medium ( $\alpha$-MEM) (GIBCO-Invitrogen). The final concentration of collagen was determined at 2 $\mathrm{mg} / \mathrm{mL}$. Thereafter, $250 \mu \mathrm{L}$ of collagen solution were placed in each well with a plastic coverslip (24-well plate) (Corning Incorporated, NY, USA) and maintained in an incubator under a humidified atmosphere of $5 \% \mathrm{CO}_{2}$ in $95 \%$ air at $37^{\circ} \mathrm{C}$ for 15 $\mathrm{min}$, until the solution polimerized into a collagen gel matrix. After polymerization, samples were 15.8 $\mathrm{mm}$ in diameter and $2 \mathrm{~mm}$ in length.

Two-dimensional surfaces were prepared by diluting the collagen on phosphate buffered saline (PBS) (GIBCO-Invitrogen) until the final concentration of $50 \mu \mathrm{L} / \mathrm{mg}$. After that, $100 \mu \mathrm{L}$ of collagen dilution was placed in each well with a plastic coverslip (24-well plate) and maintained at room temperature (RT) for 1 hour. After this period, the remaining solutions were aspirated.

\section{Cell proliferation}

Cell proliferation was evaluated by 3-(4,5-dimethylthiazol-2-yl)-2,5diphenyltetrazolium bromide (MTT) (Sigma) assay ${ }^{19}$ at 3,7 and 10 days. Cells were incubated with $10 \%$ MTT $(5 \mathrm{mg} / \mathrm{mL})$ in culture medium at $37^{\circ} \mathrm{C}$ for 4 hours. The medium was then aspirated from the well, and $1 \mathrm{~mL}$ of acid isopropanol $(0.04 \mathrm{NHCl}$ in isopropanol) was added to each well.

The plates were then stirred on a plate shaker 
for $5 \mathrm{~min}$, and $200 \mu \mathrm{L}$ of this solution were transferred to a 96-well format using opaque-walled transparent-bottomed plates (Fisher Scientific). Optical density was read at $570 \mathrm{~nm}$ on the plate reader ( $\mu$ Quant Biotek Instruments, VT, USA) and data were expressed as absorbance.

\section{Alkaline phosphatase activity}

Alkaline phosphatase (ALP) activity was assayed as the release of thymolphthalein from thymolphthalein monophosphate using a commercial kit (Labtest Diagnostica, MG, Brazil). Briefly, $50 \mu \mathrm{L}$ of thymolphthalein monophosphate were mixed with $0.5 \mathrm{~m}$ of $0.3 \mathrm{M}$ diethanolamine buffer, $\mathrm{pH} 10.1$, and left for $2 \mathrm{~min}$ at $37^{\circ} \mathrm{C}$. The solution was then added to $50 \mu \mathrm{L}$ of the lysates obtained from each well for $10 \mathrm{~min}$ at $37^{\circ} \mathrm{C}$. For color development, 2 $\mathrm{mL}$ of $0.09 \mathrm{M} \mathrm{Na}_{2} \mathrm{CO}_{3}$ and $0.25 \mathrm{M} \mathrm{NaOH}$ were added. After $30 \mathrm{~min}$, absorbance was measured using a spectrophotometer ( $\mu$ Quant Biotek Instruments) at $590 \mathrm{~nm}$ and ALP activity was calculated from a standard curve using thymolphthalein resulting in a range from 0.012 to $0.4 \mu \mathrm{mol}$ thymolphthalein/h/ $\mathrm{mL}$. Data was expressed as ALP activity normalized by total protein content (modification of the Lowry method) $)^{17}$.

Indirect ilmmunofluorescence for localization of alkaline phosphatase (ALP) and osteopontin (OPN)

At 7 and 14 days, cells were fixed for 10 min at RT using $4 \%$ paraformaldehyde in $0.1 \mathrm{M}$ phosphate buffer (PB), pH 7.2. After washing in $\mathrm{PB}$, they were processed for immunofluorescence labeling. Cells were permeabilized with $0.5 \%$ Triton X-100 in PB for 10 min, followed by blocking with $5 \%$ skimmed milk in PB for 30 min. Primary monoclonal antibodies to ALP (anti-ALP, 1:100, B4-78) (Developmental Studies Hybridoma Bank, Iowa, USA) and osteopontin (anti-OPN, 1:800, MPIIIB10-1) (Developmental Studies Hybridoma Bank) were used, followed by a mixture of Alexa Fluor 594 (red fluorescence)-conjugated goat antimouse secondary antibody (1:200) (Molecular Probes - Invitrogen, MD, USA) and Alexa Fluor 488 (green fluorescence)-conjugated phalloidin (1:200) (Molecular Probes - Invitrogen) for $50 \mathrm{~min}$ at RT in a humidified environment, for the detection of actin cytoskeleton and cell periphery. Replacement of the primary monoclonal antibody with PB was used as control. All antibody incubations were performed in a humidified environment for 60 min at RT. Between each incubation step, the samples were washed three times ( 5 min each) in PB. Before mounting for microscope observation, samples were briefly washed with $\mathrm{dH}_{2} \mathrm{O}$ and cell nuclei stained with DAPI (1:300) (Molecular Probes - Invitrogen) for $5 \mathrm{~min}$. Afterwards, the coverslip containing 3D collagen gel, 2D collagen and the control were carefully placed face down on glass slides and mounted with Vectashield antifade (Vector Laboratories, CA, USA). The control and bi-dimensional samples were examined under epifluorescence using a Leica DMLB light microscope (Leica, Bensheim, Germany), with N Plan (X10/0.25, X20/0.40) and HCX PL Fluotar (X40/0.75) objectives, outfitted with a Leica DC 300F digital camera, 1.3 Megapixel CCD. The acquired digital images were processed with Adobe Photoshop software (version 7.0) (Adobe Systems Inc., CA, USA). The three-dimensional samples were observed with a confocal fluorescence laser-scanning microscope (Leica TCS-SP2 SE laser scanning system).

\section{Gene expression analysis using real-time PCR}

To determine the relative expression level of osteogenic markers, alkaline phosphatase (ALP), osteopontin (OPN), osteocalcin (OC), collagen I (COL I) and runt-related transcription factor 2 (RUNX2) were analysed by real-time polymerase chain reaction (RT-PCR) on days 7 and 14. For these analyses of gene expression, the plating density was $4 \times 104$ cells/well on the three-dimensional scaffolds. $\beta$-actin (ACTB) was evaluated as a control for constitutive gene expression. The gene expression analysis was performed by real-time PCR as described below.

Total RNA was isolated using the TRIZOL ${ }^{\circledR}$ reagent (GIBCO-Invitrogen) according to the manufacturer's instructions. The concentration of RNA was determined by optical density at a wavelength of $260 \mathrm{~nm}$ using GeneQuant (Amersham Biosciences, NJ, USA). The RNA purity was determined with A260/A280 (System for RT-PCR) (Invitrogen). Complementary DNA (cDNA) was synthesized using $1 \mu \mathrm{g}$ of RNA through a reverse transcription reaction (High-capacity CDNA Reverse Transcription Kits) (Applied Biosystems, CA, EUA). Real-time PCR quantitative $\mathrm{mRNA}$ analyses were performed in CFX96 (Bio-Rad, CA, USA) using SybrGreen system (Applied Biosystems). SybrGreen PCR MasterMix, specific primers and $2.5 \mathrm{ng}$ of CDNA were used in each reaction. The standard PCR conditions were $50^{\circ} \mathrm{C}(2 \mathrm{~min}), 95^{\circ} \mathrm{C}(10 \mathrm{~min}), 40$ cycles of 15 seconds at $95^{\circ} \mathrm{C}$, and a final cycle of 20 min with increasing temperature from $60^{\circ} \mathrm{C}$ to $95^{\circ} \mathrm{C}$, followed by the standard denaturation curve. The primers used are demonstrated in Figure 1.

Each assay was run in duplicate. For mRNA analysis, the relative level of gene expression was calculated in reference to both $\beta$-actin expression in the sample and its respective control using the cycle threshold (Ct) method ${ }^{16}$. 


\begin{tabular}{|c|c|c|}
\hline Genes & & Primer sequences \\
\hline \multirow[t]{2}{*}{ B-actin } & Forward & 5'-ATGTTTGAGACCTTCAACA-3' \\
\hline & Reverse & 5'-CACGTCAGACTTCATGATGG-3' \\
\hline \multirow[t]{2}{*}{ RUNX2 } & Forward & 5'-TATGGCACTTCGTCAGGATCC-3' \\
\hline & Reverse & 5`-AATAGCGTGCTGCCATTCG-3` \\
\hline \multirow[t]{2}{*}{ COL I } & Forward & 5'-TGACGAGACCAAGAACTG-3' \\
\hline & Reverse & 5'-CСATCCAAACCACTGAAACC-3' \\
\hline \multirow[t]{2}{*}{ ALP } & Forward & 5'-ACGTGGCTAAGAATGTCATC-3' \\
\hline & Reverse & 5'-CTGGTAGGCGATGTCCTTA-3' \\
\hline \multirow[t]{2}{*}{ OPN } & Forward & 5'-AGACACATATGATGGCCGAGG-3' \\
\hline & Reverse & 5'-GGCCTTGTATGCACCATTCAA-3' \\
\hline \multirow[t]{2}{*}{$\mathrm{OC}$} & Forward & 5'-CAAAGGTGCAGCCTTTGTGTC-3' \\
\hline & Reverse & 5'-TCACAGTCCGGATTGAGCTCA-3' \\
\hline
\end{tabular}

Figure 1- Primer sequences for real-time polymerase chain reaction

\section{Mineralized bone-like nodule formation and calcium content}

At 10 and 14 days, the cultures were fixed with $4 \%$ formaldehyde in $\mathrm{PB}, \mathrm{pH} 7.2$, for 2 hours at RT and washed in the same buffer. The samples were then dehydrated in a graded series of alcohol and stained with $2 \%$ alizarin red $\mathrm{S}$ (Sigma), $\mathrm{pH}$ 4.2 , for $8 \mathrm{~min}$ at RT. The mineralized bone-like nodule formation was visualized by epifluorescence microscopy and the calcium content was obtained by the quantification of color, which was evaluated by the colorimetric method ${ }^{10}$ and expressed as optical density. The absorbance was measured in a spectrophotometer ( $\mu$ Quant Biotek Instruments) at a wavelength of $405 \mathrm{~nm}$.

\section{Statistical analysis}

The data presented in this work were a pool of three separate experiments in cell cultures established from three different donors. All experiments were carried out in quintuplicate $(n=5)$ with the exception of real-time PCR, which was conducted in triplicate $(n=3)$. Nonparametric data were submitted to the Kruskal-Wallis test, for independent samples, followed by Dunn's test for multiple comparisons. Parametric data were submitted to one-way analysis of variance (ANOVA) followed by a Tukey's test, which was used for multiple comparisons. SigmaStat program (version 3.5) (Statcon, Witzenhausen, Germany) was used and a value of $\mathrm{p}<0.05$ was considered statistically significant.

\section{RESULTS}

\section{Cell proliferation}

In general, all groups presented an increased proliferation rate over time. MTT assay showed that cell proliferation was affected by the culture period ( 3 days $<7$ days $<10$ days). Cultures on $2 \mathrm{D}$
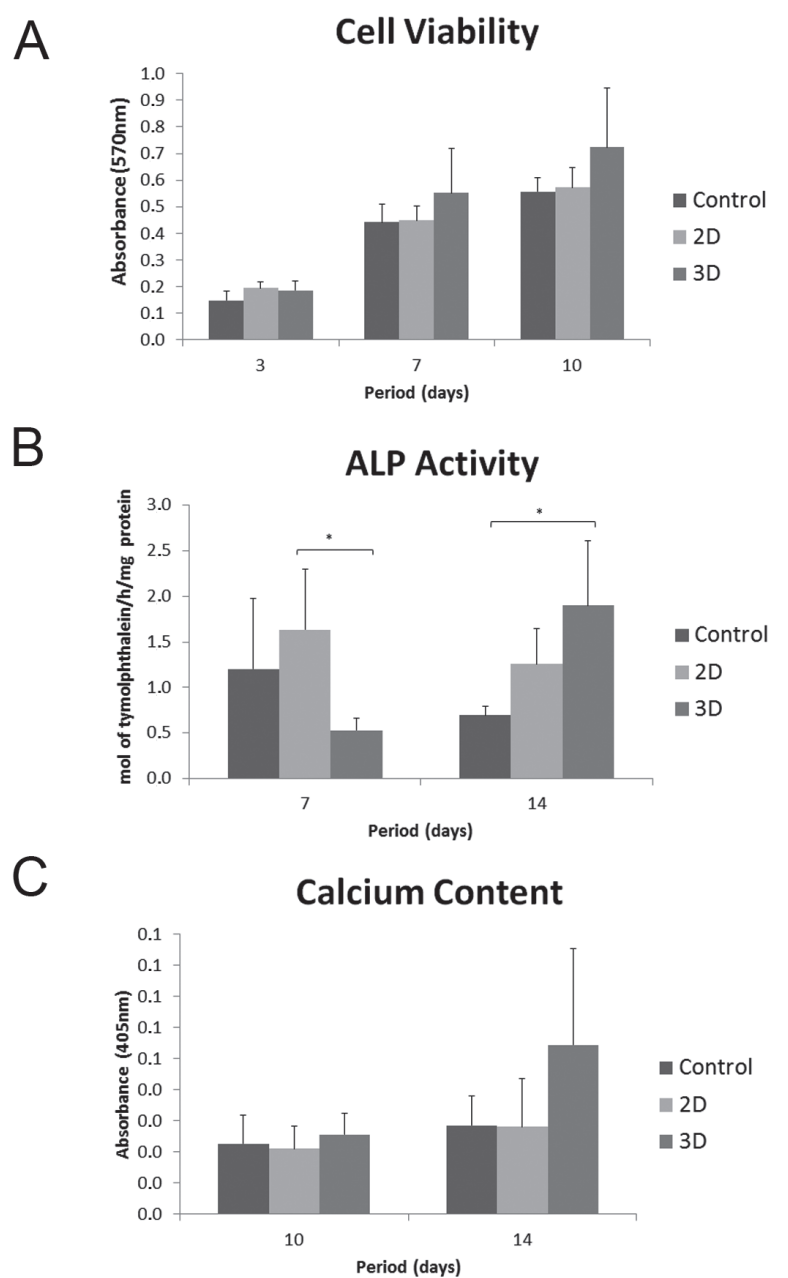

Figure 2- A - Cell viability analysis (MTT assay) at 3, 7 and 10 days. The optical density was read at $570 \mathrm{~nm}$, and data were expressed as absorbance; B - Alkaline phosphatase (ALP) activity ( $\mu \mathrm{mol}$ thymolphthalein/h/mg protein) at 7 and 14 days; $C$ - Calcium content at 10 and 14 days. The optical density was read at $405 \mathrm{~nm}$, and data were expressed as absorbance. * $p<0.05$ (KruskalWallis - post-test Dunn's) 
and 3D collagen produced an increased rate of cell proliferation in comparison with control surface; however, there was no significant difference between the groups (Figure $2 \mathrm{~A}$ ).

\section{Alkaline phosphatase activity}

A significant lower degree of ALP activity was observed on 3D cultures when compared with 2D $(p<0.05)$ at 7 days. However, the cells seeded on

3D collagen produced a significant higher level of ALP activity than those seeded on control surface $(p<0.05)$ at 14 days (Figure $2 B)$.

Indirect immunofluorescence for location of alkaline phosphatase (ALP) and osteopontin (OPN)

Epifluorescence revealed that cells were adherent and well-spread on control and 2D,
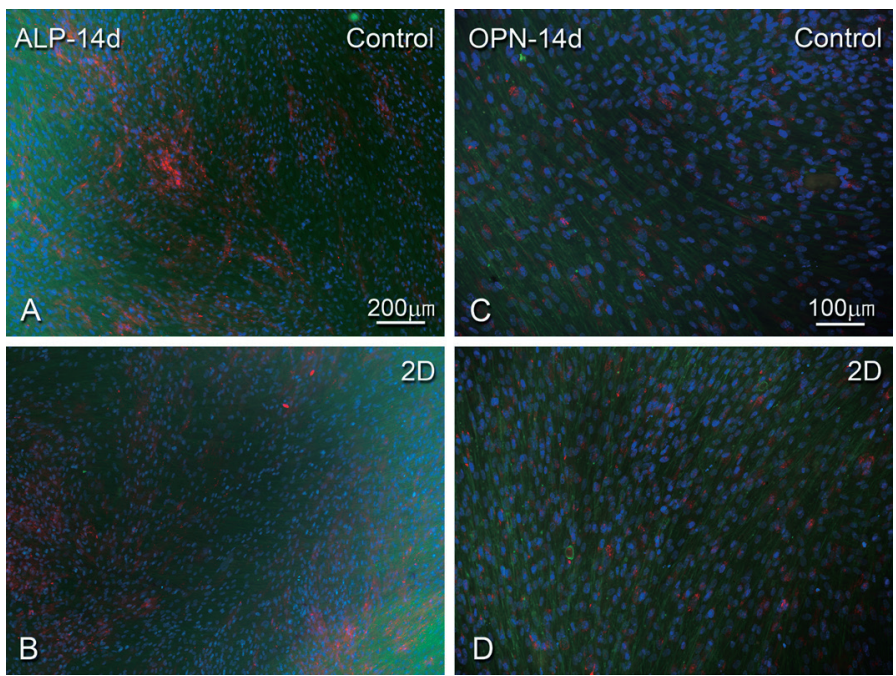

Figure 3- hPDLF cells grown on bi-dimensional surfaces, control and at 14 days. Epifluorescence of actin cytoskeleton labeling (phalloidin labeling, green fluorescence), DNA stain (DAPI, blue fluorescence), alkaline phosphatase (ALP) (A-B) and osteopontin (OPN) labeling (C-D) (red fluorescence). Bar A-B: $200 \mu \mathrm{m}$ and Bar C-D: $100 \mu \mathrm{m}$
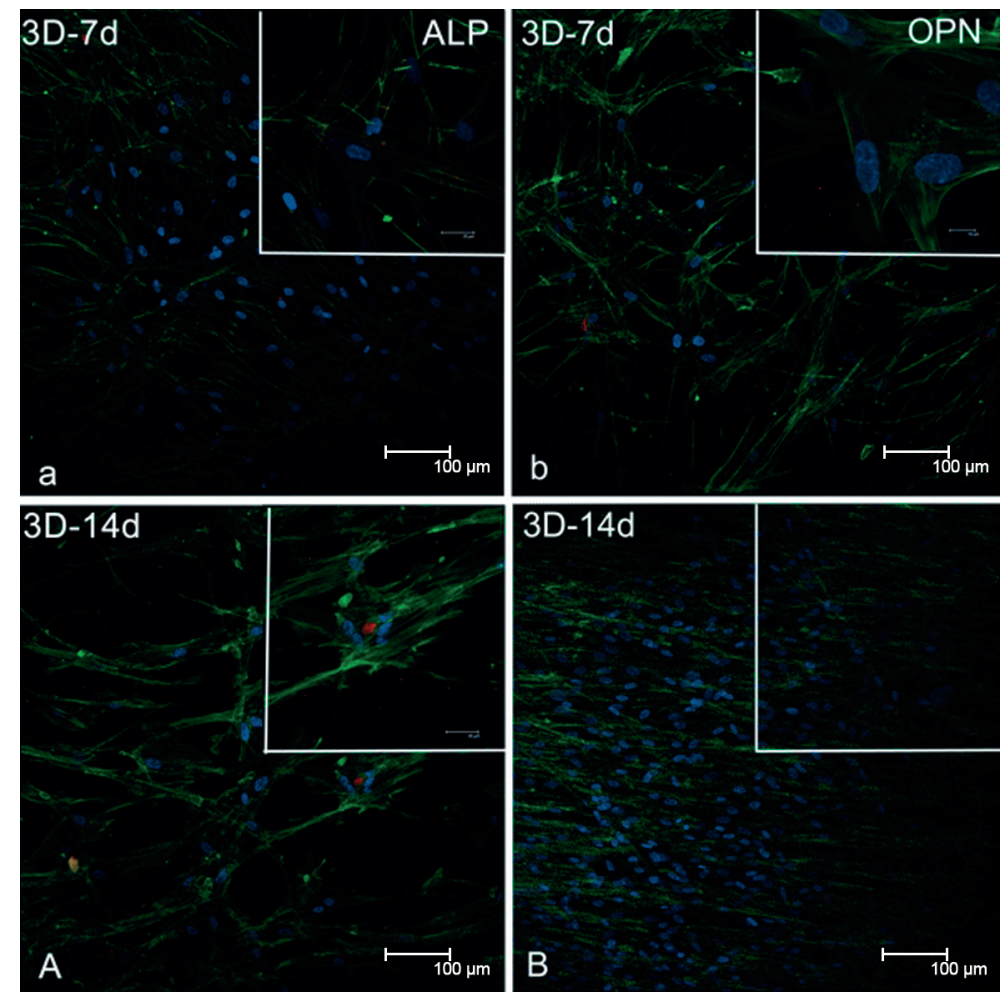

Figure 4- hPDLF cells grown on three-dimensional surface (3D) at 7 days (a and b) and 14 days (A and B). Fluorescence of actin cytoskeleton labeling (phalloidin labeling, green fluorescence), DNA stain (DAPI, blue fluorescence), alkaline phosphatase (ALP) (a and A) and osteopontin (OPN) (b and B) red fluorescence observed in confocal microscopy 
exhibiting a flat morphology of predominantly fusiform or polygonal shapes, with a well-organized cytoskeleton, and defined actin stress fibers, shown in Figure 3 as green. A denser cell layer can be observed, indicating that cell proliferation has occurred (Figure 3A).
ALP and OPN immunolabeling was not observed in cells seeded on control and 2D collagen at 7 days (data not shown). The confocal microscopy showed the cell growth inside the collagen gel. A natural spindle-shaped morphology and a small proportion of ALP and OPN labeling mainly perinuclear and
ALP

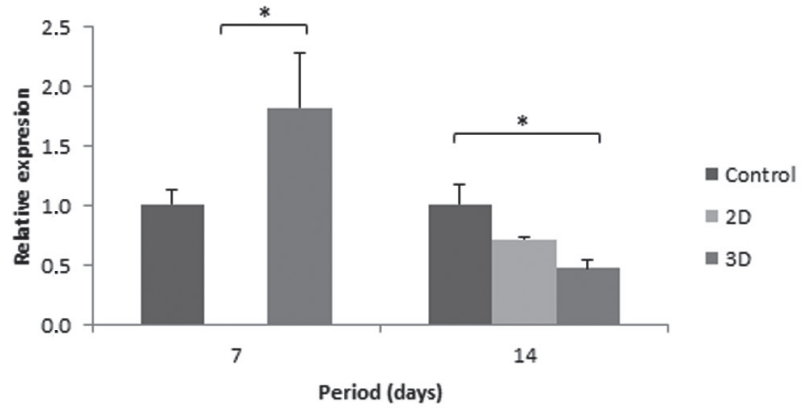

OPN

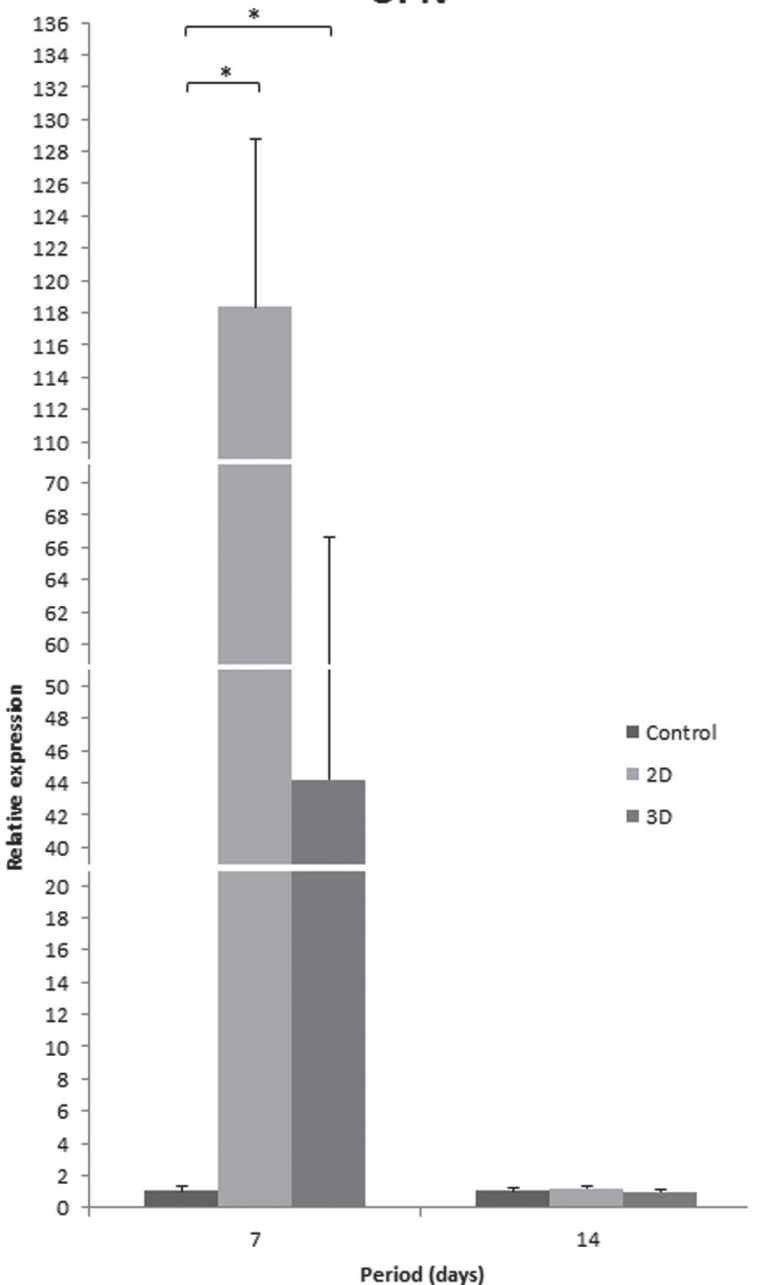

COLI

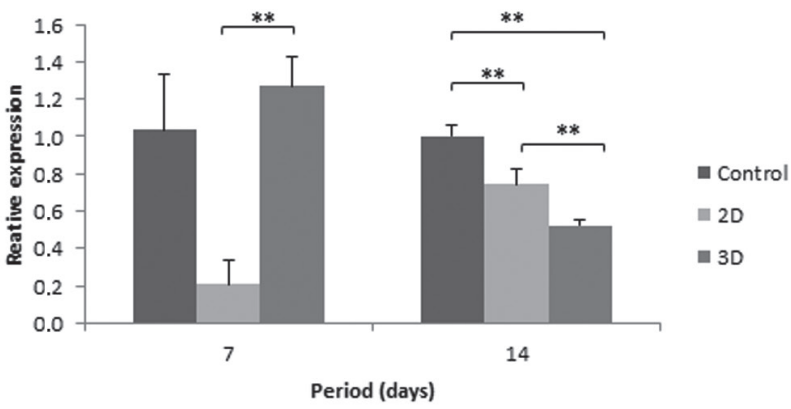

RUNX2

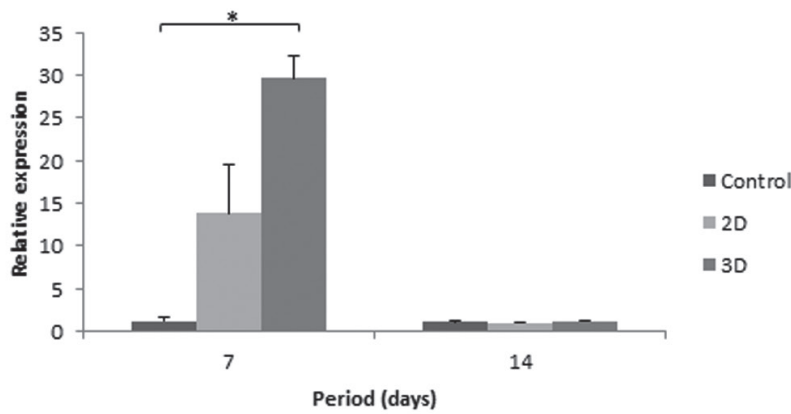

OC

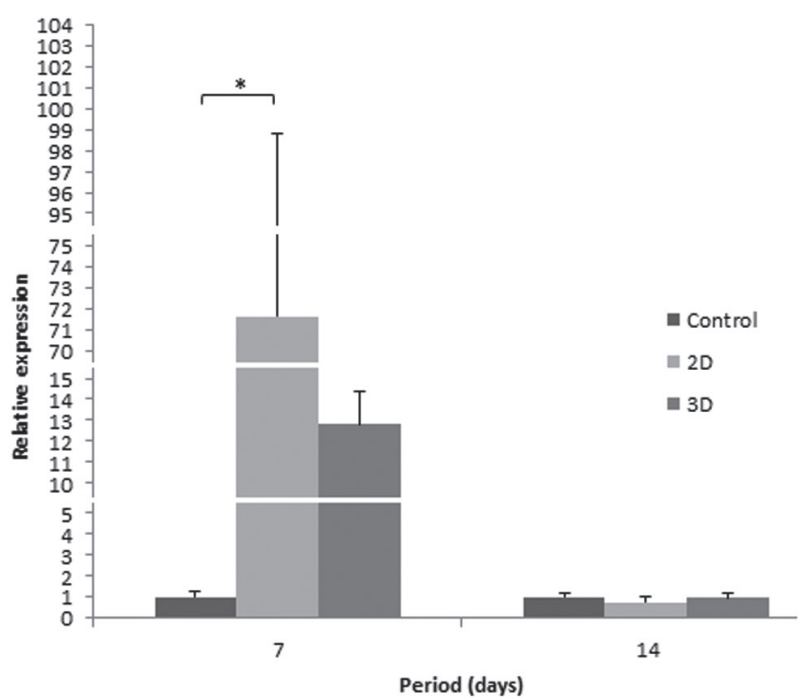

Figure 5- Gene expression of COL I, ALP, RUNX2, OPN and OC in hPDLF cultured on different groups at 7 and 14 days using real-time polymerase chain reaction (PCR). Data were calculated as the relative expression of the target mRNA normalized to $\beta$-actin and to control (calibrator) and are reported as mean \pm SD. ${ }^{*} p<0.05$ (Kruskal-Wallis - post-test Dunn's) and ${ }^{* *} \mathrm{p}<0.05$ (ANOVA - post-test Tukey's) 
punctate deposits throughout the cytoplasm were observed in cells seeded on 3D cultures. OPN immunolabeling appeared mainly around the nucleus in cells on 3D collagen (Figures 4A and 4B).

At 14 days, there was a similar, discernible extracellular accumulation of ALP immunolabeling on the control (Figure 3A) and 2D cultures (Figure 3B). ALP immunolabeling appeared mainly around the nucleus in cells on the 3D cultures (Figure 4A). A perinuclear and extracellular OPN immunolabeling was occasionally detected on 2D collagen (Figure 3D) and control surfaces (Figure 3C). Cells seeded on 3D collagen showed perinuclear and punctate OPN immunolabeling deposits mainly throughout the cytoplasm (Figure 4B).

\section{Gene expression analysis using real-time PCR}

The osteoblastic phenotype was confirmed at the transcriptional level by mRNA expression of the genes encoding COL I, ALP, RUNX2, OPN and OC. Three-dimensional conditions contribute to the upregulated expression levels of all evaluated genes at 7 days. The expression of ALP and COL I was significantly higher on 3D when compared with 2D culture, and OPN and RUNX2 relative gene expression was significantly higher on 3D when compared with control surface. However, ALP and COL I expression levels were downregulated in cells on 2D and 3D collagen at 14 days, and COL I gene expression was significantly lower in 3D than in 2D culture. Furthermore, OPN, RUNX2 and OC gene expression decreased in all evaluated groups at 14 days compared with 7 days (Figure 5).

\section{Mineralized bone-like nodule formation and calcium content}

The alizarin red-stained cultures did not exhibit areas of calcified matrix on all evaluated groups at 10 days (data not shown). However, at 14 days, stained areas and the beginning of mineralized nodule formation was observed by microscopy in all groups, independently of the presence of the particles (Figure 6). The calcium content measure by extraction of alizarin red $\mathrm{S}$ from the mineralized matrix was greater on the 3D culture at 10 and 14
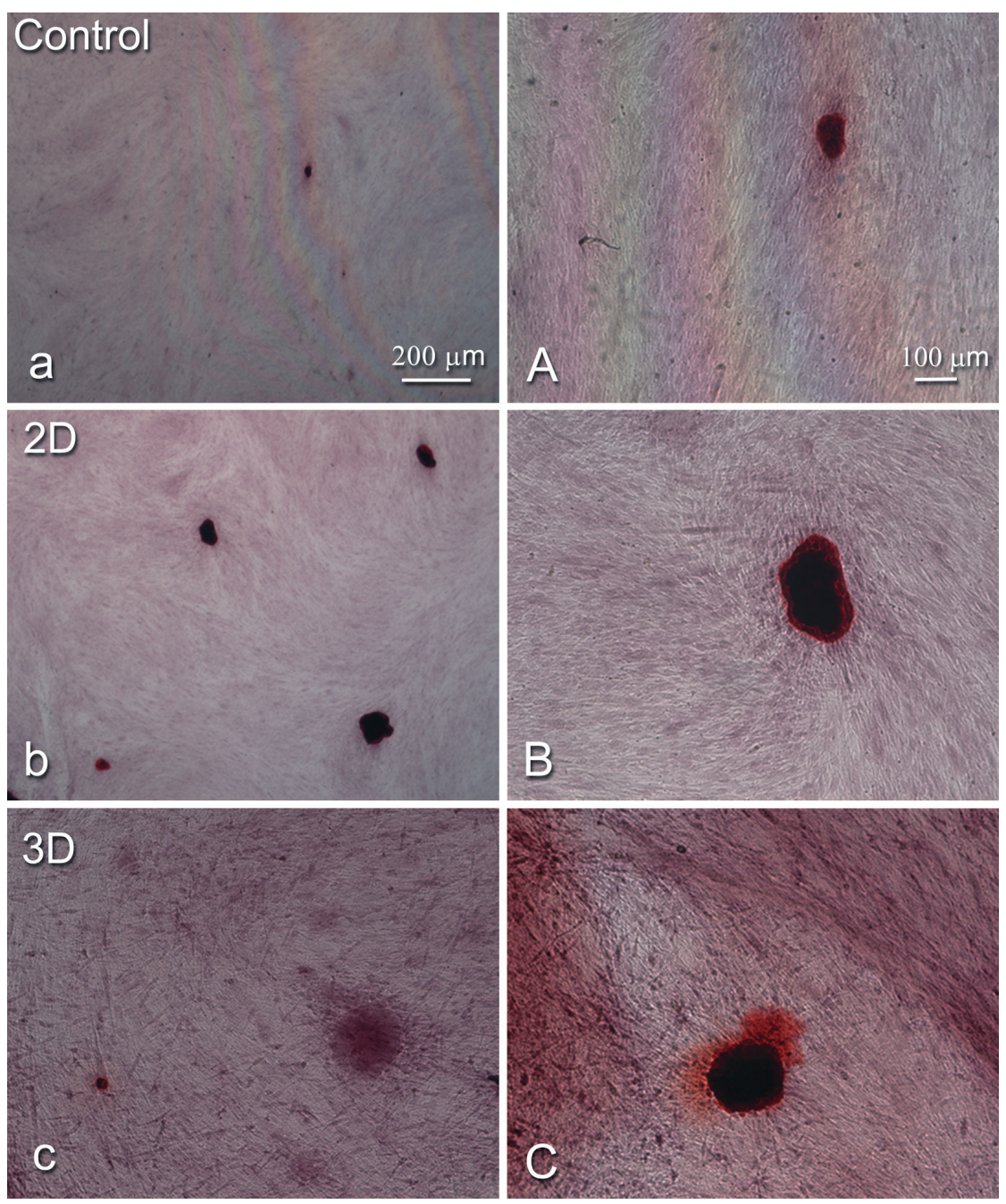

Figure 6- Alizarin red staining of mineralized nodule formation in hPDLF cultures. Control (a and A), 2D collagen (b and B), and 3D collagen (c and C). Bar a-c: $200 \mu \mathrm{m}$ and Bar A-C: $100 \mu \mathrm{m}$ 
days, however it was not statistically significant (Figure 2C).

\section{DISCUSSION}

Tissue engineering approaches in periodontal regeneration probably open up a new context in periodontal therapy. The cells within the PDL tissue play a central role in this periodontal healing process. Several studies in vitro have demonstrated that hPDLFs exhibit both fibroblastlike and osteoblast-like phenotypes such as high ALP activity, production of bone-like matrix proteins and formation of mineralized nodules $4,21,22,31$. Furthermore, cells cultured in collagen gels/surfaces have demonstrated their ability to acquire tissuelike phenotypes and differentiated function ${ }^{25}$.

In the present study, we confirmed that threedimensional collagen supported cell proliferation and contributed to an osteoblastic phenotype expression of hPDLF, since it favored ALP activity, mineralized nodule formation and expression of ALP, COL I, OPN, RUNX2 and OC, genes related to this phenotype.

The cell proliferation rate showed an increase on $2 \mathrm{D}$ and $3 \mathrm{D}$ collagen in up to 10 days, showing a normal proliferative index in all evaluated groups. Although no significant differences were found between the groups at 7 and 10 days, cells seeded on 3D collagen had the highest proliferation levels in these periods. This is in accordance with another study that showed higher cell viability rate in three-dimensional cultures, compared with twodimensional cultures ${ }^{8}$. The three-dimensionality may have contributed to a larger area of cell proliferation.

In vivo hPDL cells are embedded in ECM, whose major part consists of different types of collagen, though predominantly collagen type I. That is the reason for the use of collagen type $\mathrm{I}$ in this study. Unlike a 2D monolayer culture, in which cells typically adopt spread morphology, cells residing in the collagen matrix show a true 3D morphology and distribution. This situation is similar to the natural PDL. However, differences remained between cell morphology on the solid surfaces (coverslip) and in the center. These findings are not surprising and are in agreement with $2 \mathrm{D}$ versus $3 \mathrm{D}$ culture systems. For example, fibroblasts in 2D cultures exhibit a flat morphology with dorsal-ventral polarity and large lammellipodia, whereas in a 3D matrix, cells show a natural spindle-shaped morphology 8,30 . This phenomenon may be related to the ECM environment in which cells that are encapsulated need to overcome surrounding physical impediments to proliferate or migrate ${ }^{9}$.

Morphological analysis by fluorescence microscopy showed that cells grown on control surfaces and 2D collagen presented the same pattern of spreading and immunolabeling to ALP and OPN (observed only at 14 days). Analysis by confocal microscopy showed the cell growth inside of collagen gel. In spite of that labeling suggesting the osteoblastic phenotype, its biological significance is still unknown.

Earlier reports have shown a greater ALP activity in hPDLF $^{1,23,26}$. In the present study the ALP activity level was significantly higher on 2D than on 3D cultures $(p<0.05)$ at 7 days. However, at 14 days it was observed that the cells seeded on 3D collagen produced a level of ALP activity significantly higher than the control surface $(p<0.05)$. There is a hypothesis that, at 7 days, the three-dimensional collagen is still stable and intact and fibroblasts embedded in the collagen gel are closely surrounded by the collagen network that creates a biochemical confinement ${ }^{2}$, which could delay the ALP activity or its withdrawal at the early stage. However, at 14 days, collagen contraction and remodeling resulting from the action of proteolytic enzymes secreted primarily by fibroblasts were observed. This may have contributed positively to the ALP activity at the late stage. This contraction of the collagen complex at 14 days was consistent with the observations of other studies ${ }^{20,27}$.

Although the calcium content was not influenced by the three-dimensional collagen at 7 days, threedimensionality played an important role in the formation of a mineralized matrix at 14 days.

The periodontal ligament has osteogenic potential. PDL fibroblasts show RUNX2 ${ }^{15}$ and ALP gene expression both in situ and in vitro ${ }^{11,31}$, whereas the OC are only expressed in vitro ${ }^{13}$. Differentiation of PDL fibroblasts into either osteoblasts or cementoblasts in situ occurs depending on the environment ${ }^{24}$. In the present study, we show that the three-dimensionality conditions affect the phenotype of hPDLF, since a significant increase of RUNX2 expression, which are genes related to an osteoblastic phenotype, was noted in 3D. At 14 days, a gene expression decrease of all markers was observed, and it was more relevant for OPN, RUNX2 and $O C$. These results demonstrate that the early expression of genes related to mineralization may have allowed the mineralization at later periods. These results differ from other studies with rat calvaria osteoblasts, bone marrow cells, cell line MC3T3-E1 and periodontal ligament cells ${ }^{5,6}$, which reported that $\mathrm{OC}$ gene expression was maintained once mineralization nodules formation was initiated. It is believed that the OC, RUNX2 and OC expression decrease at 14 days is related to apoptosis during cell differentiation. Studies have shown the occurrence of apoptosis when mineralization advances $^{18}$. When periodontal ligament cells were cultured in supplemented medium with ascorbic 
acid, $\beta$-glycerophosphate and dexamethasone, the expression levels of OC, OPN and BSP were maximized at 14 days and minimized at 21 days ${ }^{14}$.

These results indicate the potential of hPDLF to exhibit phenotypic characteristics, consistent with osteoblast-like cells when cultured on 3D collagen and osteogenic conditions. This potential was further demonstrated by ALP activity, calcified nodule formation and gene expression of osteogenic markers. This phenomenon is in accordance with the in vivo PDL environment, in which cells at the bone and cement borders are prone to differentiate into osteoblasts or cementoblasts, whereas the ones in the center retain a fibroblastic phenotype. However, the distribution of cells on the scaffolds needs to be investigated, as it plays an important role on cell activities and the differentiation study.

There is still much to be elucidated about the ability of the periodontal ligament cells to maintain their distinct phenotypic characteristics on 3D cultures in vitro, which is important to provide a reliable framework in which we can study and manipulate these cells for bioengineering and periodontal regeneration.

\section{REFERENCES}

1- Arceo N, Sauk JJ, Moehring J, Foster RA, Somerman MJ. Human periodontal cells initiate mineral-like nodules in vitro. J Periodontol. 1991;62:499-503.

2- Berthod F, Hayek D, Damour O, Collombel C. Collagen synthesis by fibroblasts cultured within a collagen sponge. Biomaterials. 1993;14:749-54.

3- Caton J, Nyman S, Zander H. Histometric evaluation of periodontal surgery. II. Connective tissue attachment levels after four regenerative procedures. J Clin Periodontol. 1980;7:224-31. 4- Cho MI, Matsuda N, Lin WL, Moshier A, Ramakrishnan PR. In vitro formation of mineralized nodules by periodontal ligament cells from the rat. Calcif Tissue Int. 1992;50:459-67.

5- Choi JY, Lee BH, Song KB, Park RW, Kim IS, Sohn KY, et al. Expression patterns of bone-related proteins during osteoblastic differentiation in MC3T3-E1 cells. J Cell Biochem. 1996;61:609-18. 6- Choi MH, Noh WC, Park JW, Lee JM, Suh JY. Gene expression pattern during osteogenic differentiation of human periodontal ligament cells in vitro. J Periodontal Implant Sci. 2011;41:167-75. 7- Chou AM, Sae-Lim V, Lim TM, Schantz JT, Teoh SH, Chew CL, et al. Culturing and characterization of human periodontal ligament fibroblasts - a preliminary study. Mater Sci Eng C. 2002;20:77-83. 8- Cukierman E, Pankov R, Stevens DR, Yamada KM. Taking cellmatrix adhesions to the third dimension. Science. $2001 ; 294: 1708$ 12.

9- Friedl P, Bröcker EB. The biology of cell locomotion within threedimensional extracellular matrix. Cell Mol Life Sci. 2000;57:41-64. 10- Gregory CA, Gunn WG, Peister A, Prockop DJ. An Alizarin red-based assay of mineralization by adherent cells in culture: comparison with cetylpyridinium chloride extraction. Anal Biochem. 2004;329:77-84.

11- Groeneveld MC, Van den Bos T, Everts V, Beertsen W. Cellbound and extracellular matrix-associated alkaline phosphatase activity in rat periodontal ligament. Experimental Oral Biology Group. J Periodontal Res. 1996;31:73-9.

12- Inanc $B$, Elcin $A E$, Elcin YM. Osteogenic induction of human periodontal ligament fibroblasts under two- and three-dimensional culture conditions. Tissue Eng. 2006;12:257-66.
13- Ivanovski S, Haase HR, Bartold PM. Expression of bone matrix protein mRNAs by primary and cloned cultures of the regenerative phenotype of human periodontal fibroblasts. J Dent Res. 2001;80:1665-71.

14- Iwata T, Yamato M, Zhang Z, Mukobata S, Washio K, Ando $\mathrm{T}$, et al. Validation of human periodontal ligament-derived cells as a reliable source for cytotherapeutic use. J Clin Periodontol. 2010;37:1088-99.

15- Jiang H, Sodek J, Karsenty G, Thomas H, Ranly D, Chen J. Expression of core binding factor Osf2/Cbfa-1 and bone sialoprotein in tooth development. Mech Dev. 1999;81:169-73.

16- Livak KJ, Schmittgen TD. Analysis of relative gene expression data using real-time quantitative PCR and the 2(-Delta Delta $\mathrm{C}(\mathrm{T})$ ) Method. Methods. 2001;25:402-8.

17- Lowry $\mathrm{OH}$, Rosebrough NJ, Farr AL, Randall RJ. Protein measurement with the Folin phenol reagent. J Biol Chem. 1951;193:265-75.

18- Lynch MP, Capparelli C, Stein JL, Stein GS, Lian JB. Apoptosis during bone-like tissue development in vitro. J Cell Biochem. 1998;68:31-49.

19- Mosmann T. Rapid colorimetric assay for cellular growth and survival: application to proliferation and cytotoxicity assays. ] Immunol Methods. 1983;65:55-63.

20- Neeley WW, Carnes DL, Cochran DL. Osteogenesis in an in vitro coculture of human periodontal ligament fibroblasts and human microvascular endothelial cells. J Periodontol. 2010;81:139-49.

21- Nohutcu RM, McCauley LK, Koh AJ, Somerman MJ. Expression of extracellular matrix proteins in human periodontal ligament cells during mineralization in vitro. J Periodontol. 1997;68:320-27. 22- Nojima N, Kobayashi M, Shionone M, Takahashi N, Suda T, Hasegawa K. Fibroblastic cells derived from bovine periodontal ligaments have the phenotypes of osteoblasts. J Periodontal Res. $1990 ; 25: 179-85$.

23- Pi SH, Lee SK, Hwang YS, Choi MG, Lee SK, Kim EC. Differential expression of periodontal ligament-specific markers and osteogenic differentiation in human papilloma virus 16-immortalized human gingival fibroblasts and periodontal ligament cells. J Periodontal Res. 2007;42:104-13.

24- Pitaru S, McCulloch CA, Narayanan SA. Cellular origins and differentiation control mechanisms during periodontal development and wound healing. J Periodontal Res. 1994;29:81-94.

25- Schindler M, Nur E-Kamal A, Ahmed I, Kamal J, Liu HY, Amor N, et al. Living in three dimensions: 3D nanostructured environments for cell culture and regenerative medicine. Cell Biochem Biophys. 2006;45:215-27.

26- Somerman MJ, Archer SY, Imm GR, Foster RA. A comparative study of human periodontal ligament cells and gingival fibroblasts in vitro. J Dental Res. 1988;67:66-70.

27- Suaid FF, Ribeiro FV, Gomes TR, Silvério KG, Carvalho MD, Nociti FH Jr, et al. Autologous periodontal ligament cells in the treatment of Class III furcation defects: a study in dogs. J Clin Periodontol. 2012;39:377-84.

28- Velazquez OC, Snyder R, Liu ZJ, Fairman RM, Herlyn M. Fibroblast-dependent differentiation of human microvascular endothelial cells into capillary-like 3-dimensional networks. FASEB J. 2002;16:1316-8.

29- Xiao Y, Qian H, Young WG, Bartold PM. Tissue engineering for bone regeneration using differentiated alveolar bone cells in collagen scaffolds. Tissue Eng. 2003;9:1167-77.

30- Yamada KM, Cukierman E. Modeling tissue morphogenesis and cancer in 3D. Cell. 2007;130:601-10.

31- Yamashita Y, Sato M, Noguchi T. Alkaline phosphatase in the periodontal ligament of the rabbit and macaque monkey. Arch Oral Biol. 1987;32:677-8. 